\title{
Case Analysis of the ZC Company's AS Power Project Investment Decision-Making
}

\author{
Jian-Fei Leng, Qun Zhang, Xiang-Nan Wang \\ Business School of Hohai University, Nanjing, China \\ Email: 1245206010@qq.com
}

Received 29 September 2015; accepted 8 November 2015; published 11 November 2015

Copyright (C) 2015 by authors and Scientific Research Publishing Inc.

This work is licensed under the Creative Commons Attribution International License (CC BY). http://creativecommons.org/licenses/by/4.0/

(c) (i) Open Access

\begin{abstract}
First, combined with relevant theories of modern investment decision-making, this paper took AS power engineering project of ZC Company for instance, analyzed objective function of power engineering investment structure in ZC Company. Second, this paper analyzed investment decisionmaking structure of AS power engineering project in ZC Company, and obtained specific results of investment decision-making, and the related results were verified. Through analysis and exploration, this paper has a scientific impact on ZC Company for the AS power project investment, while it's hoped that it can play a role in electric power engineering projects of other companies in China. So it can better promote the development of electrical engineering investment in electrical industry.
\end{abstract}

\section{Keywords}

Investment Decision, Benefit, Electrical Engineering, Risk, Investment Structure

\section{The Introduction}

In recent years, with the continued development of western economy, the electricity consumption is continually growing across the country, the national level timely puts forward the grand blueprint of "restart the silk road", our country electric power system will continue to expand unceasingly in the future and the power market demand increases unceasingly, thus creating the good prospects of electric power project investment. But due to the constant transformation of the economic system, and competitive power of related enterprises, especially for new energy policy inclination and support, it leads the traditional electric power enterprise's investment to face a lot of challenges and pressures from the state, society, market and so on. Thus electric power enterprises should consider various influencing factors to optimize investment to achieve input costs and output benefits. Also 
through scientific choosing in investment objects and effective use in investment decision to make investment benefit and risk management of the power engineering project equilibrium, we can improve the electric power company in the overall market competitiveness and promote the sustainable development of the company.

The AS power project is the traditional investment project of ZC Company, mainly including investment of thermal power, maintenance and testing $\&$ training. These investments are vital to the development of company, especially the electrical enterprises. So this paper takes AS power engineering project of ZC Company for instance, from the angle of financial management and research, analyzes the AS power engineering project investment structure, and expounds significance about the investment structure budget plan for AS electric power project, trying to provide new ideas for similar electric power enterprise project investment.

\section{Literature Review}

There are many studies on project investment structure decision-making at home and abroad. Chen (2008) [1] proposed that domestic enterprise investment project decisions needed a comprehensive study from the enterprise overall strategy, product market feasibility, technical feasibility, project feasibility and financial feasibility analysis etc. Ross (1978) [2] pointed out that the investment opportunity of project risk could be considered as another options - real options. Meng (2011) [3] established the power extension project evaluation index system by economic evaluation and risk analysis of the electric extension project. Wang (2007) [4] put forward that the company should control possible risks from the angle of time and scale when making investment decision. Jia (2008) [5] changed the power project decision-making system by using AHP, made the decision result more scientific by quantifying research problem. Liu Yan and Zhang Wei (2007) took use of the theory of investment portfolio to solve the assignment problem of traditional power project. In order to reduce the risk and guarantee recycling, they discussed preliminarily the investment portfolio issues of electric power project, through the establishment of the mathematical model to determine the investment shares in different electric power projects.

To sum up, the influence factors of project investment are numerous, but these studies are mostly limited to theoretical aspects, rarely on the actual case. So this paper analyses the specific project investment decisionmaking, hoping that it can play a role in other enterprises.

\section{Project Background and General Situation}

\subsection{ZC Company's Background and a Preliminary Assumption of AS Power Projects}

ZC Company short for China Huadian Corporation, and is the state-owned listed companies, one of the power generation enterprises in China. The headquarters is located in Beijing. ZC Company's main business include all kinds of electric power production, the heat production and supply system, the development of one-time energy relevant to electric power, research and development and manufacture of power system equipment, engineering construction, research and development technology provides, etc. It is the largest power engineering system integration service providers all over the world, the company has a complete power engineering industry chain, and independent intellectual property (power production technology) reached international advanced level. The international market share in the world first for many years, projects in more than 60 countries around the world.

For a long time, north China area is the main supply of ZC Company electric power production. With the continuous improvement of the region's economic level, electricity demand is also raising, especially in the peak period, electricity demand obviously greater than supply. in order to effectively alleviate the situation, after the board of directors agree, ZC Company investment department take investigation and research for AS power engineering project, made preliminary feasibility study report of the AS power engineering project, and through the relevant experts review. AS power engineering project is a traditional investment project of ZC Company, the construction goal of the project include thermal power development, design, investment, construction management, etc., at the same time it also engaged in some maintenance, testing, electric power training and consulting services, which is related to thermal power. AS power project started in January 2016, the investment fund is 120 million RMB, and the investment conditions are shown in Table 1.

\subsection{Investment Structure Optimization Objective Function Analysis of ZC Company Electric Power Engineering Project}

From the three aspects of the efficiency, reliability and expansibility to determine power engineering investment 
Table 1. ZC Company AS power project investment conditions table.

\begin{tabular}{cc}
\hline Investment fund & 120 million RMB \\
\hline $\begin{array}{c}\text { The field of investment } \\
\text { The method of decision making } \\
\text { Decision-making way }\end{array}$ & Thermal power, maintenance, testing and training \\
The source of the decision & Scheme comparison \\
\hline
\end{tabular}

structure of ZC Company, because the implementation of ZC Company power engineering is focus on these three aspects. The goal of Power engineering project investment decision analysis is all of the selected three aspects of subjective utility value maximum. So analyze electric power project investment decision-making, is to convert multiple objective decision, at the same time under the condition of capital, project constraints, balance and optimize the special plan for different management apartment.

\subsubsection{ZC Company Power Engineering Efficiency Maximization}

The biggest goal that ZC Company investment in the construction of power engineering is to make profits, so the project investment structure model should be in a certain constraint conditions to maximize economic benefits. The economic benefits maximization of power engineering can be expressed as subjective utility evaluation maximization of selected project economic profits. If AS engineering investment project have $\mathrm{N}$ subprojects, the library of I project investment have MI item, maximize economic benefits is expressed by the following formula:

$$
\operatorname{Max} A=\sum_{i=1}^{n} \sum_{j=1}^{m i} E_{j}^{i} \times X_{j}^{i}
$$

$A$ is the goal solving of formula, which is the general profit value of all considered items. $A_{j}^{i}$ is single item of general profit, $E_{j}^{i}$ is expected return rate in each item, $X_{j}^{i}$ express each item investment proportion (the same below).

\subsubsection{Reliability Maximization of ZC Company Power Engineering}

Reliability is an important goal of ZC Company power engineering implementation, so the power engineering project investment structure model is to maximize reliability under certain constraints. Then the objective function can be expressed in the following formula:

$$
\operatorname{Max} B=\sum_{i=1}^{n} \sum_{j=1}^{m i} R_{j}^{i} \times X_{j}^{i}
$$

\subsubsection{Development Maximization of ZC Company Power Engineering}

For ZC Company power engineering, project development indexes is also very important, the project development indicators plays a significant role in sustainable development of the enterprise, and thus it also become an important goal of ZC Company power engineering investment. For ZC Company power engineering, the objective function can be said with the following formula:

$$
\operatorname{Max} \mathrm{C}=\sum_{i=1}^{n} \sum_{j=1}^{m i} D_{j}^{i} \times X_{j}^{i}
$$

The $C$ is goal solution of formula, which is developmental profit value of each considered item, and $C_{j}^{i}$ is developmental profit value of each item.

Through the comprehensive analysis on three indicators subjective utility evaluation result of the ZC Company power engineering, which obtained respectively three objective function of ZC Company power engineering project investment. Therefore, ZC Company power project investment decision-making is through the relevant formula, index to find out the comprehensive benefit maximization of three objective functions of the ZC Company power engineering. 


\subsection{The Constraint of ZC Company Power Engineering Project Investment Structure}

\subsubsection{The Constraint Relation among ZC Company Power Engineering Projects}

As the project in the library of ZC Company electric power engineering construction project involves many areas, and under every field has numerous projects. So there are many links and constraints among projects in the alternative project investment library. Seen from ZC Company electric power engineering in the past, there are mainly the following constraints:

First: Project subordinate constraints

When portfolio analyze on investment project in the alternative library of ZC Company electric power project, subordinate constraints relationship between projects should be considered. Specifically, project subordinate constraints is mainly in view of the dependent relationship between the various projects, namely when big infrastructure investment is chose, that is associated with the relatively small size of the infrastructure investment is possible. If alternative project $\mathbf{J}$ and $\mathrm{I}$ have constraints, and then only when the $\mathrm{J}$ project is selected, then I project can be selected. Namely, $X_{j}=1, X_{i}=1$ or $X_{i}=0$, but if the $X_{j}=0, X_{i}=0$, these dependent constraints with the formula can be expressed as:

$$
X_{i}-X_{j} \leq 0(i, j \in X)
$$

Second: Exclusive project constraints

In investment decision analysis, part of project options can only choose, the project between different administrative departments exist the exclusive constraint relation. If alternative project $J$ and $I$ is constrain relation, then illustrate $J$ and $I$ will not be able to exist at the same time, it can be expressed as with formula:

$$
X_{i}+X_{j} \leq 1 \quad(i, j \in X)
$$

Third: Project complementary constraints

Complementary constraint relation between the projects main show that when a project invests, and another project would be invested at the same time. When a project without investing requires another project also go offline. Use the formula can be expressed as:

$$
X_{i}-X_{j}=0(i, j \in X)
$$

\subsubsection{Capital Constraints between ZC Company Electric Power Engineering Projects}

In the process of ZC Company electric power project investment decision-making, there are many projects in the optional libraries, but because of the restrictions of power engineering investment quota, only part of projects in the libraries can be performed, the important premise of investment decision-making is that make sure all of the money must not be greater than investment amount of the project. When the total investment budget of project was determined, if just according to every item profit in the project optional libraries to decide, it is easier to cause imbalance that some project expenditure over budget while some project investment too small, causing the actual investment do not agree with the target. So in terms of capital, not only control total amount of investment, also control each project investment amount.

First of all, control total amount of all the project investment, which not exceed annual investment plan. If the project investment is divided into $\mathrm{N}$ items, subprojects I have MI items in its library, the item profit value respectively is $I_{1} \cdots I_{M I}$, total capital constraint relation of ZC Company power engineering investment can be expressed as:

$$
\sum_{i=1}^{n} \sum_{j=1}^{m i} I_{j}^{i} \times X_{j}^{i} \leq I
$$

Secondly, all areas of project investment have upper limit and lower limit, the $I^{\text {th }}$ investment field of ZC Company power engineering has MI items, each project investment quota respectively is $I_{1} \cdots I_{M I}$, the $I^{\text {th }}$ constraint relation can be expressed as:

$$
\sum_{j=1}^{m} I_{j}^{i} \times X_{j}^{i} \leq I^{i}
$$

\subsection{Constraint Conditions of ZC Company AS Power Engineering Project}

In accordance with the relevant provisions, ZC Company put forward constraints of each project according to 
the development goals and the annual total investment amount, as shown in Table 2:

Index constraints analysis: overall investment quota of the five major construction projects in Table 2 should be less than 120 million. But no matter from upper or lower limit constraints, the overall investment quota of the five major construction projects are beyond the plan investment quota, so in order to guarantee the smooth implementation of investment, not all the projects are within the year.

\section{Investment Model Solve of ZC Company AS Power Project}

\subsection{Set up Investment Structure Model of ZC Company Power Engineering Project}

It can be seen from the above analysis, based on the comprehensive consideration of economy, reliability and development, to set up investment structure model of ZC Company power engineering project. Through comprehensive consideration of three aspects, making investment structure model of ZC Company power engineering project investment can bring comprehensive benefit maximization.

At the same time, under the condition of fixed investment structure, balance investment in different areas, and give full consideration on dependent, exclusive and complementary constraints between every field projects. In the multi-objective decision-making model, no matter use what kind of solution, it is unlikely to make all of $g$ investment objectives optimizing, the most practical and effective method is filtered according to the importance of different investment objectives, so as to achieve the balance of the investment objectives, to get a relatively effective optimization scheme.

For calculating investment structure of ZC Company power engineering project, adopt the simplified method, make $\lambda=\left(\lambda_{1}, \lambda_{2}, \lambda_{3}, \cdots, \lambda_{n}\right)$ as each target weighted coefficient of power engineering investment structure in ZC Company, and $\sum_{j=1}^{n} \lambda_{j}=1$, then many decision problems can be converted to single target decision-making to plan and solve. According to the weighted coefficient to transform economy, reliability and expansibility, it can get comprehensive benefit function of project investment structure:

$$
\operatorname{Max} M=\lambda_{1}(x) \times E+\lambda_{2}(x) \times D+\lambda_{3}(x) \times R
$$

In this function, $M$ is the objective function of the model, on behalf of the total benefit of selected projects, namely the selected project's contribution to the ZC Company power engineering.

Ultimate goal of ZC Company electric power project investment is to achieve comprehensive benefit maximization, that is to say, the plan with maximum $M$ value is the optimal scheme of electric power investment, including $E$ represents the overall economic benefits subjective utility value of the chosen project, $R$ represents the profits of reliability, $D$ represents developmental profits considered, $\lambda_{1}(x), \lambda_{2}(x), \lambda_{3}(x)$ shows the each target weighted coefficient in the process of project decision-making.

Based on the above analysis we can draw ZC Company benefit functions of the investment structure in ZC Company electric power engineering project and the constraint relationship between the projects and capitals,

Table 2. Constraint conditions of ZC Company AS power project.

\begin{tabular}{|c|c|c|c|c|}
\hline \multirow{10}{*}{ 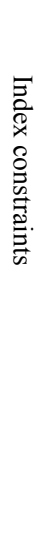 } & \multicolumn{2}{|l|}{ Index investment upper limit constraints } & \multicolumn{2}{|l|}{ Lower limit index investment constraints } \\
\hline & Bigger investment in infrastructure & 7900 & Bigger investment in infrastructure & 7500 \\
\hline & small size of the investment in infrastructure & 1900 & small size of the investment in infrastructure & 1500 \\
\hline & $\begin{array}{l}\text { The investment of production and technical } \\
\text { innovation }\end{array}$ & 2000 & $\begin{array}{c}\text { The investment of production and technical } \\
\text { innovation }\end{array}$ & 1900 \\
\hline & Sporadic purchase investments & 760 & Sporadic purchase investments & 750 \\
\hline & Information technology investment & 440 & Information technology investment & 450 \\
\hline & \multicolumn{4}{|c|}{ Total investment capital: less than 120 million } \\
\hline & \multicolumn{4}{|c|}{ The small size infrastructure investment less than $17 \%$ the total investment capital } \\
\hline & \multicolumn{4}{|c|}{ Sporadic purchase investments less than $8 \%$ total investment capital } \\
\hline & \multicolumn{4}{|c|}{ Only infrastructure investment online, Sporadic purchase investments online } \\
\hline
\end{tabular}


set up following power engineering project investment structure:

$$
\left\{\begin{array}{l}
\operatorname{Max} M=\lambda_{1}(x) \times E+\lambda_{2}(x) \times D+\lambda_{3}(x) \times R \\
\sum_{i=1}^{n} \sum_{j=1}^{m i} I_{j}^{i} \times X_{j}^{i} \leq I \\
\sum_{j=1}^{m} I_{j}^{i} \times X_{j}^{i} \leq I^{i} \\
X_{i}+X_{j} \leq 1 \\
X_{i}-X_{j} \leq 0 \\
X_{i}-X_{j}=0 \\
X_{j}^{i}=0 \text { 或 } 1
\end{array}\right.
$$

\subsection{The Determination of the Usual Weight of ZC Company AS Power Engineering Project}

Method of AHP is often used to determine the usual weight of AS power engineering project. But due to complicated calculation process of method of AHP, and the heavy influence of the mind, so in contrast, if take use of method of FAHP [6], it is more accurately to determine the usual weight of project investment.

Method of FAHP generally done through the following three steps:

The first step: Construct the fuzzy complementary matrix [7]. Power project construction should strictly in accordance with the standards and goal of electric power engineering construction in China, to determine the importance of each project investment, according to the importance of the AS electric power project to set up following the fuzzy complementary matrix:

$$
R_{1}=\left[\begin{array}{lll}
0.4 & 0.3 & 0.3 \\
0.7 & 0.5 & 0.5 \\
0.7 & 0.5 & 0.5
\end{array}\right]
$$

The second step: constructs the fuzzy consistent matrix, transformed according to the following formula:

$$
r_{i j}=\frac{r_{i}-r_{j}}{2 \times n}+0.5\left(r_{i}=\sum_{k=1}^{n} r_{i k}(i=1,2, \cdots, n)\right.
$$

According to the above formula, transformed the fuzzy complementary matrix into a fuzzy consistent matrix $R_{2}$ :

$$
R_{2}=\left[\begin{array}{ccc}
0.4 & 0.35 & 0.3 \\
0.75 & 0.75 & 0.5
\end{array}\right]
$$

The third step: the calculation of the weight of model [8]. According to the formula below:

$$
W=\frac{1}{n}-\frac{1}{2 a}+\frac{1}{n \times a} \times \sum_{k=1}^{n} r_{i k}\left(a=\frac{n-1}{2}\right)
$$

The usual weight of AS project can be concluded:

$$
\left(W_{1}, W_{2}, W_{3}\right)=(0.216,0.331,0.363)
$$

\subsection{Variable Weight Determination of ZC Company AS Power Project}

Seen from the calculation of usual weight, the economy, reliability and expansibility of ZC Company AS power project were $0.216,0.331$ and 0.363 , the three usual weights are determined in the overall investment environment. Because of the features of the ZC Company AS power project, in the process of investment decision, it is necessary to adjust target weight of the project, target weight, so that each project indicators get balance. From view of ZC Company AS power project investment, satisfaction index of economy, reliability and expansibility were respectively $95 \%, 96 \%$ and $95 \%$. According to the following variable weight formula: 


$$
W(X)=\frac{w_{0} * s(x)}{\sum w_{j} * S_{j}(x)}=\frac{w_{i}}{x_{i}} / \sum \frac{w_{i}}{x_{i}}(i=1,2,3)
$$

Through calculation, the engineering index as shown in Table 3 .

As we can see in Table 3, the variable weights of economy index, the reliability index, development index of ZC Company AS electric power engineering projects are respectively " $0.211,0.321,0.371$ ", satisfaction degree was $95 \%, 96 \%$ and $84 \%$ respectively. It can be seen that investment development is lower, compared variable weights with usual weights, the economy index and reliability index weight has decreased, but the developmental index weight increased. This means that reliability and economy of ZC Company AS power project is relatively high, but the developmental slightly insufficient, therefore, for ZC Company AS power project, it is importance to promote development ability.

\subsection{Model Solve of ZC Company AS Power Engineering Project}

According to relevant results of investment structure of ZC Company AS power engineering project, it can be concluded the investment quota, project numbers and the number of actually projects actually online of $\mathrm{ZC}$ Company AS power engineering project, as shown in Table 4.

As can be seen from Table 4, five major construction projects have 53 small projects, total investment of 46 projects is 118.64 million, with total investment quota should not exceed 120 million, there are seven small projects will not be able to online in this year.

\subsection{Establishments the Amount of Investment in AS Electric Power Project}

According to the upper limit of each item investment, and establish the amount of investment in AS electric power project. In Table 5, big size of infrastructure investment accounts for largest percentage (66\%) of the total amount of investment, this not only conforms to the characteristics of electric power engineering project investment, and accord with the fact of ZC Company AS power project. In addition, the proportion of the small size of infrastructure investment and production, the technical transformation investment is higher, also have accounted for $15 \%$ of the total amount of investment, it shows that ZC Company AS power for technical renovation project investment is very necessary.

Table 3. The operation of ZC Company AS power engineering project.

\begin{tabular}{cccccc}
\hline \multirow{2}{*}{ Engineering name } & $\begin{array}{c}\text { Investment } \\
\text { quota }\end{array}$ & Ondex & Economy & Reliability & Expansibility \\
\cline { 3 - 4 } & Operation value & 0.211 & 0.321 & 0.371 \\
\hline $\begin{array}{c}\text { AS power engineering } \\
\text { project }\end{array}$ & 120 million & Satisfaction index & $95 \%$ & $96 \%$ & $84 \%$ \\
\hline
\end{tabular}

Table 4. Results of ZC Company AS power project investment structure.

\begin{tabular}{|c|c|c|c|}
\hline Investment project & $\begin{array}{l}\text { Project numbers in the } \\
\text { library }\end{array}$ & $\begin{array}{l}\text { Actually investment project } \\
\text { numbers }\end{array}$ & Investment quota \\
\hline Bigger investment in infrastructure & 14 & 14 & 7765 \\
\hline small size of the investment in infrastructure & 13 & 11 & 1471 \\
\hline $\begin{array}{l}\text { The investment of production and } \\
\text { technical innovation }\end{array}$ & 10 & 9 & 1802 \\
\hline Sporadic purchase investments & 11 & 9 & 579 \\
\hline Information technology investment & 5 & 3 & 247 \\
\hline Amount to & 53 & 46 & 11,864 \\
\hline
\end{tabular}


Table 5. ZC Company AS power project investment proportion.

\begin{tabular}{ccc}
\hline Name & \multicolumn{2}{c}{ Total amount of investment } \\
\cline { 2 - 2 } Total construction investment & Sum up \\
percentage & 11,864 & $100.00 \%$ \\
Bigger investment in infrastructure & & $66 \%$ \\
small size of the investment in infrastructure & 7765 & $12 \%$ \\
The investment of production and technical innovation & 1471 & $15 \%$ \\
Sporadic purchase investments & 1802 & $5 \%$ \\
Information technology investment & 579 & $2 \%$ \\
\hline
\end{tabular}

As can be seen from Table 2, investment quota of ZC Company power engineering project is 120 million, projects investment in five areas can satisfy the upper and lower bounds of each project investment at the same time, therefore, Table 5 is the best solve of ZC Company AS power project invest decision-making.

\section{Conclusion}

This paper takes investment in AS power engineering project of ZC Company plans in 2016 as the research object, from the angle of financial management and research, analyzes investment structure of AS power engineering project, and classifies and evaluates the operational indicator of ZC Company AS power project to provide the basis for balance of AS power engineering project investment. Thus it shows that the scientific budget of the investment structure has significant impacts on AS electric power project, trying to provide new ideas for project investment of the similar electric power enterprise.

\section{References}

[1] Chen, Y.-L. (2008) Research on Investment Project Decision-Making and Method of Enterprise. Journal of Chongqing Institute of Technology (Sociology), 11, 56-59.

[2] Ross, S.A. (1978) A Simple Approach to the Valuation of Risks Income Streams. Journal of Business, 51, 453-457.

[3] Meng, Z. (2011) Investment Portfolio Study on Oil and Gas Exploration Project. China Petroleum University, Qingdao and Dongying.

[4] Wang, L. (2007) Risk Causes and Control Countermeasures of Project Investment Decision-Making. Market Modernization, 7, 156-158.

[5] Jia, G. (2008) Simply Makes Use of the Method of AHP in the Investment Decision-Making. Journal of Information Science and Technology, 23, 512-513.

[6] Zhang, W.-G., Qin, M. and Chen, C.-W. (2011) Fuzzy Optimization Method of the Project Investment Portfolio. Journal of Management, 6, 938-942.

[7] Marshall, J.F., Vipul and Bansal, K. (1992) Financial Engineering. Allan \& Bacon Inc., New York.

[8] Huang, X.-Q. (2011) Apply to Fuzzy Comprehensive Evaluation Method in Electric Power Engineering Project. Journal of Security Technology of Electric Power, 8, 23-27. 